\title{
Estimation of the Relation between the Dispersion Features of Free Internal Waves and the Density Field Vertical Structure in the Barents and Kara Seas
}

\author{
A. A. Bukatov, N. M. Solovei*, E. A. Pavlenko \\ Marine Hydrophysical Institute of RAS, Sevastopol, Russian Federation \\ *ne.le.7@ hotmail.com
}

Purpose. The aim of the paper is to investigate spatial-temporal dependences of the dispersion features of short-period free internal waves on the density field vertical structure in the Barents and Kara seas.

Methods and Results. Based on the linearized equations of motion of the ideal incompressible and continuously stratified fluid, the dispersion features of free internal waves in the Barents and Kara seas were studied. Solution of the main boundary problem of the Sturm-Liouville type made it possible to obtain the own frequencies of five lowest modes and the own period of the internal waves' first mode. To calculate the density field, the World Ocean Atlas 2013 reanalysis data on temperature and salinity for $1955-2012$ with resolution $0.25^{\circ} \times 0.25^{\circ}$ were applied. The relation between the dispersion features of free internal waves and the density field vertical structure was analyzed, and dispersion characteristics of theinternal waves in the Barents and Kara seas were compared.

Conclusions. During the months when the density gradients are maximal, the internal waves of the highest frequency and the shortest period are observed. Among the intra-year maximums of the buoyancy depth-averaged frequency, the highest values $\left(\approx 0.02 \mathrm{~s}^{-1}\right)$ are observed in the Barents Sea in July and August, and those of the Kara Sea - in July-September $\left(\approx 0.055 \mathrm{~s}^{-1}\right)$ and in November $\left(\approx 0.058 \mathrm{~s}^{-1}\right)$. In the same months, noted are the maximum values of the averaged natural frequencies and the minimum values of the averaged own period of the internal waves. Thus, for the wavelength $1000 \mathrm{~m}$, the highest averaged own frequency and the smallest averaged own period of the first mode in the Barents Sea constitute $0.0025 \mathrm{~s}^{-1}$ and $45 \mathrm{~min}$., and those in the Kara Sea $-0.0038 \mathrm{~s}^{-1}$ and 30 min, respectively.

Keywords: the Barents Sea, the Kara Sea, Väisälä-Brunt frequency, internal waves, dispersion relations, own frequency, own period.

Acknowledgements: The investigation is carried out within the framework of the state task on theme No. 0827-2019-0003.

For citation: Bukatov, A.A., Solovei, N.M. and Pavlenko, E.A., 2020. Estimation of the Relation between the Dispersion Features of Free Internal Waves and the Density Field Vertical Structure in the Barents and Kara Seas. Physical Oceanography, [e-journal] 27(1), pp. 18-27. doi:10.22449/1573-160X-2020-1-18-27

DOI: $10.22449 / 1573-160 X-2020-1-18-27$

(C) A.A. Bukatov, N.M. Solovei, E.A. Pavlenko, 2020

(C) Physical Oceanography, 2020

\section{Introduction}

Wave movements of sea water are observed throughout the entire World Ocean and play an important role in ocean processes. Internal waves are manifested in temperature and water salinity variations, affect turbulent mixing, vertical migrations of plankton and fish, the conditions of sound propagation in the ocean, etc. [1-3].

There are high-frequency and low-frequency internal waves [4]. The lengths of high-frequency internal waves range from several meters to several kilometers, and low-frequency ones - from several tens to several hundred kilometers. The energy 
spectrum of low-frequency internal waves has a pronounced maximum at the inertial (periods about 12 to several tens of hours) and tidal (periods about 12 and 24 hours) frequencies $[5,6]$. Free internal waves generated by tides propagate in the ocean. However, a latitude close to $74.5^{\circ}$ is critical for semidiurnal tidal internal waves, and to its north, they cannot exist in the form of free waves in the Arctic basin. It is believed that in the region of supercritical (high) latitudes, the internal wave of the semidiurnal period is destroyed as the driving force expires, generating a packet of short-period (high-frequency) waves. There is no prohibition on the existence in polar latitudes for such waves $[1 ; 7, \mathrm{p} .709-710]$.

In the present paper, the dispersion properties of free short-period internal waves in the Barents and Kara Seas are studied.

\section{Materials and Methods}

The monthly average density values were calculated using World Ocean Atlas 2013 reanalysis data on temperature and salinity from 1955 to 2012 . At the grid nodes $0.25^{\circ} \times 0.25^{\circ}$ with $5 \mathrm{~m}$ step in depth to $100 \mathrm{~m}$ horizon and $25 \mathrm{~m}$ step to $150 \mathrm{~m}$ horizon $[8,9]$. The research field: $16^{\circ}-105^{\circ} \mathrm{E}$ and $66^{\circ}-82^{\circ} \mathrm{N}$. The obtained density arrays were checked for the presence of inversions and, if necessary, were corrected by replacing the inversion quantities with values interpolated over neighboring horizons [10]. Then, the profiles of the buoyancy frequency $N(z)$ were calculated, the maximum of the Väisälä-Brunt frequency in depth $\left(N_{\max }(z)\right)$ was determined.

The study of internal waves is based on the linearized equations of motion of an ideal incompressible continuously stratified fluid. In the, neglecting the Earth rotation, to determine the vertical velocity component $W^{(n)}(z)$, the main boundary value problem of the Sturm - Liouville type [11] is obtained

$$
\frac{d^{2} W^{(n)}}{d z^{2}}+\left(\lambda^{(n)} N^{2}-k^{2}\right) W^{(n)}=0
$$

by the boundary conditions at the bottom and free surface

$$
W^{(n)}(H)=W^{(n)}(0)=0 .
$$

Here $\quad \lambda^{(n)}=\left(\frac{k}{\omega^{(n)}}\right)^{2} ; \omega^{(n)}-$ natural frequency; $k$-wave number; $H$-depth.

For numerical solution of the main boundary value problem with a given profile $N(z)$, its finite-difference approximation was constructed. The resulting system of linear algebraic equations was solved by a method based on the solution of the characteristic equation for its matrix $[11 ; 12$, p. 545]. The natural frequencies of the five lower modes and the natural period $T$ of the first mode were calculated for waves 400-1500 m long with $50 \mathrm{~m}$ step. The existence of free internal waves in the Arctic seas in this length range is confirmed by radar sensing from space [13]. 


\section{Analysis of the Results}

The geographical position of the Barents and Kara Seas, and the features of their hydrological regime determine the density stratification of waters and the dispersion of free internal waves. An indicator characterizing the water column stratification is the buoyancy frequency (Väisälä-Brunt frequency). Between the maximum of the Väisälä-Brunt frequency and the own period of the first mode in the Barents and Kara sea waters, a noticeable correspondence is traced (Fig. 1).

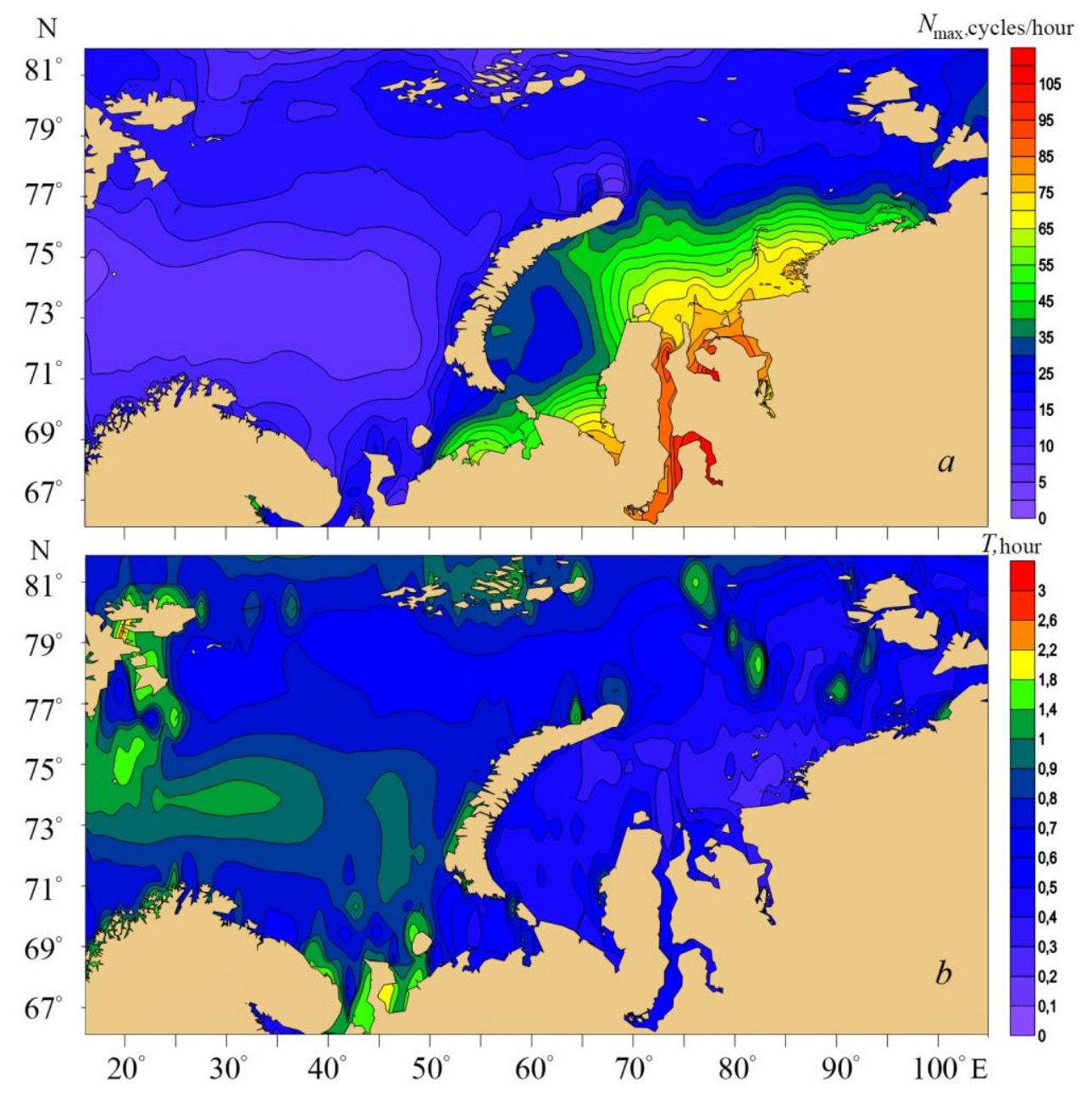

F i g. 1. Vertical distribution of the Väisälä-Brunt frequency $(a)$ and own period of the free internal waves' first mode $(b)$ in July in the Barents and Kara seas. Wavelength is $1000 \mathrm{~m}$

The calculation of the correlation dependence between the own period of the first mode and the maximum of the Väisälä-Brunt frequency (Fig. 2) showed the presence of feedback, and the correlation coefficient varies depending on the season from 0.33 (in October) to 0.59 (in February). 


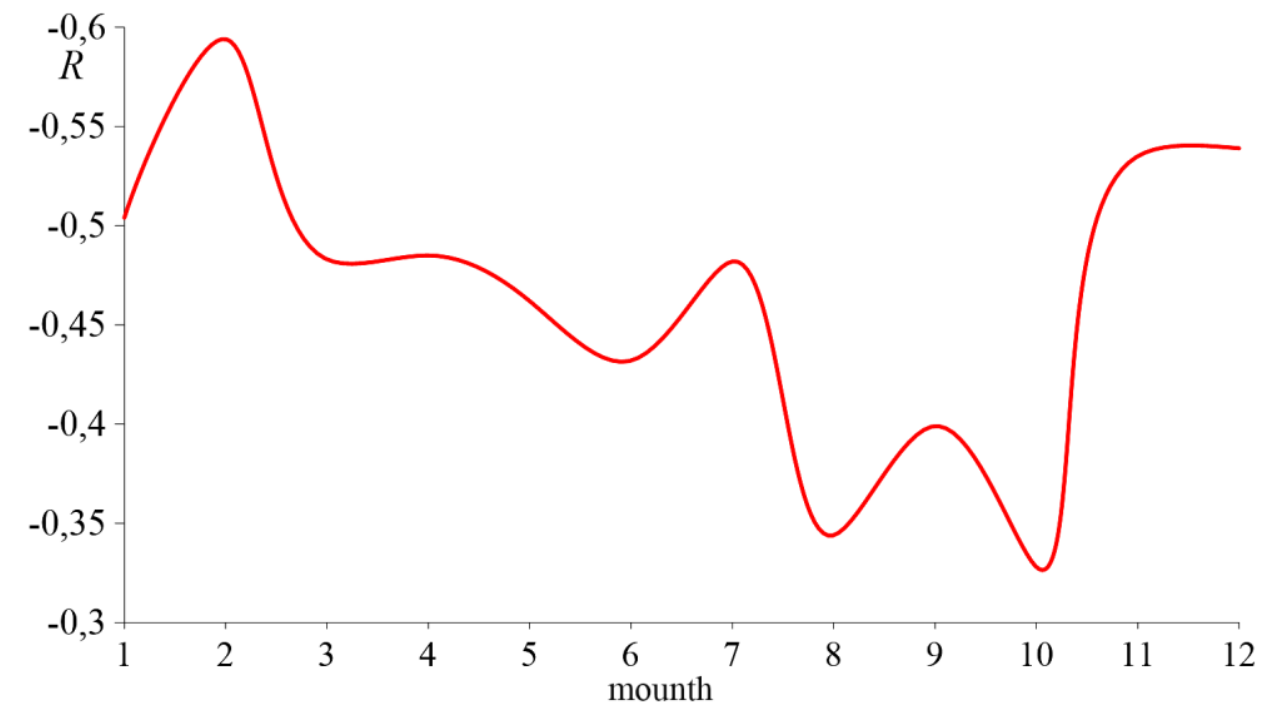

F i g. 2. Intra-year climatic variation of the correlation coefficient between the Väisälä-Brunt frequency maximum and the own period of the free internal waves' first mode in the Barents and Kara seas' water area

To study the intra-annual variability of the vertical structure of the Barents and Kara Sea density field, depth-averaging buoyancy frequency maxima $\overline{N_{\max }}(z)$. were calculated over the water areas. To analyze the annual course of the dispersion characteristics of the internal waves, the averaged own frequencies $\overline{\omega^{(n)}}$ of the five lower modes and the averaged own period $\bar{T}$ of the first mode were calculated. The graph (Fig. 3, a) shows a pronounced peak in the annual cycle $\overline{N_{\max }}(z)$ in the Barents Sea in July and August $\left(\overline{N_{\max }}(z) \approx 0,02 \mathrm{~s}^{-1}\right)$. In the Kara Sea, the highest values $\overline{N_{\max }}(z) \approx 0,055 \mathrm{~s}^{-1}$ are observed from July to September and in November (Fig. 3,a). In the same months $\overline{\omega^{(1)}}$ reaches maximum values (Fig. 3, $d$ ), and $\bar{T}$ - minimum ones (Fig. 3, c).

For wavelength $1000 \mathrm{~m}$, the highest value $\overline{\omega^{(1)}}$ and the lowest value $\bar{T}$ in the Barents Sea are respectively $0.0025 \mathrm{~s}^{-1}$ and 45 minutes, in the Kara Sea $0.0038 \mathrm{~s}^{-1}$ and 30 minutes. The correlation coefficient $R$ between intra-annual cycles of the maximum the sea-averaged buoyancy frequency and the own frequency of the first mode of the internal wave exceeds 0.9 . The value of $R$ between the intra-annual cycles $\overline{N_{\max }}(z)$ and $T$ is approximately -0.95 for both the Barents and Kara seas. In the Barents Sea, the values of averaged own frequencies for the considered wavelength range do not exceed $0.006 \mathrm{~s}^{-1}$, in the Kara Sea $-0.012 \mathrm{~s}^{-1}$. 

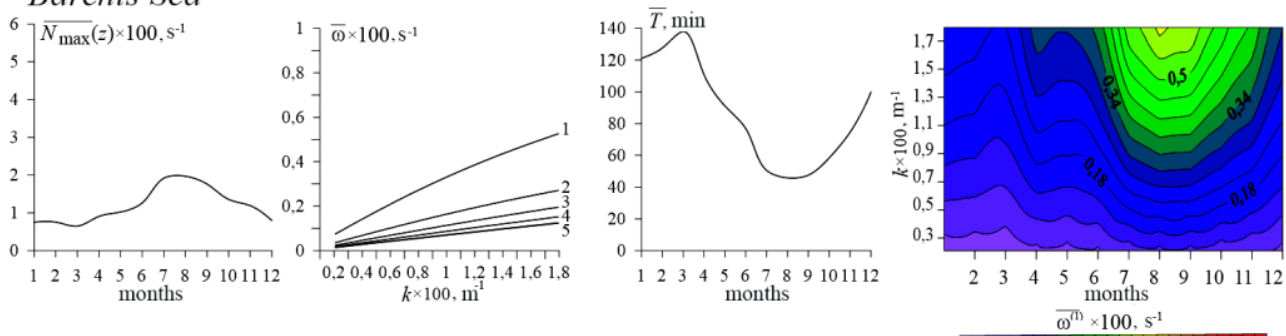

\section{Kara Sea}
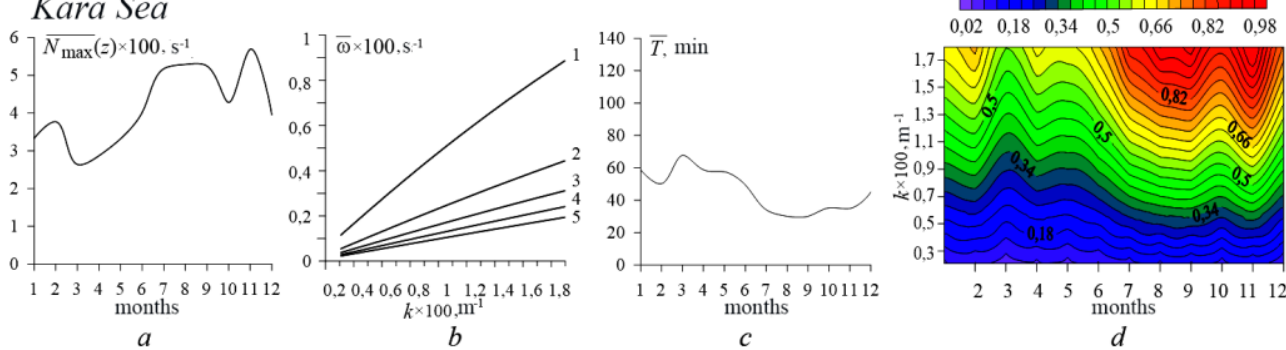

F i g. 3. Intra-year variability $\overline{N_{\max }}(z)(a)$; averaged dispersion curves of five lowest modes for July (b); intra-year variability $\bar{T}(c)$ and $\overline{\omega^{(1)}}(d)$ for the Barents and Kara seas

In the Kara Sea $\overline{N_{\max }}(z)$ is more than in the Barents one, on average three times; for the same wavelength, $\overline{\omega^{(n)}}$ is more than about two times, and $\bar{T}$ - less than about two times (Fig. 3). This difference is explained by the peculiarities of the hydrological regime of the seas, a major role in the formation of which is played by the fresh mainland waters runoff. The river runoff in the Barents Sea is small in relation to the sea area, its maximum is observed in late spring - early summer. Runoff to the Kara Sea is several times greater than the river water volume entering the Barents Sea, reaching a maximum in late summer - early autumn ${ }^{1}$. Note that the hydrological regime of the Arctic seas also depends on solar radiation. In warm season, active melting of ice leads to the desalination of the upper water layer and an increase of density gradients.

For a detailed study of the relationship between the vertical structure of the density field and the dispersion properties of internal waves, graphs of intraannual variability $\overline{N_{\max }}(z)$ and $\overline{\omega^{(1)}}$ were also constructed in the physicalgeographical regions (Fig. 4) proposed in [14-16]. Five areas are distinguished in the Barents Sea: 1) Southwest, or Medvezhinskiy; 2) Northwest, or Spitzbergenskiy; 3) North; 4) Northeast, 5) Southeast, or Kolguyevo-Vaigachskiy. Four districts are distinguished in the Kara Sea: 6) Southwest, or Yamalskiy, 7) Northwest, 8) Central, 9) North.

${ }^{1}$ Dobrovolskiy, A.D. and Zalogin, B.S, 1982. [The Seas of USSR]. Moscow: MGU. 192 p. (in Russian); Timofeev, V.T., 1946. The Barents Sea Sustainability. Problems of the Artic, (3), pp. 5-7 (in Russian). 


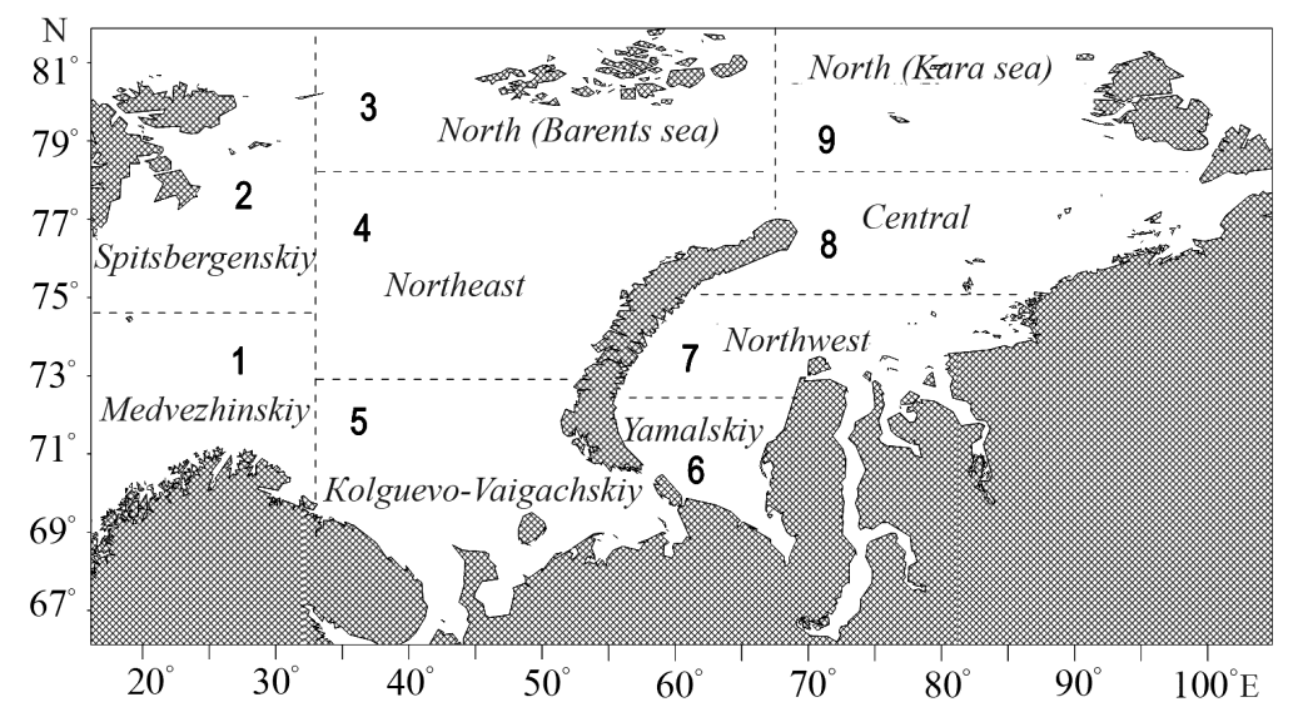

F i g. 4. Physical-geographical division into regions

Fig. 5 and 6 show that in the Barents Sea the highest values of $\overline{N_{\max }}(z)$ are determined in the North region in July $\left(0.03 \mathrm{~s}^{-1}\right)$, in the Kara Sea - in the Yamal Sea in June and in the Northwest region $\left(0.09 \mathrm{~s}^{-1}\right)$ from July to September. Maximum values of $\overline{\omega^{(1)}}$ are observed in the same areas in the same months. The highest values $\overline{N_{\max }}(z)$ in the Medvezhinskiy $\left(\approx 0.015 \mathrm{~s}^{-1}\right)$, Spitzbergenskiy $\left(\approx 0.02 \mathrm{~s}^{-1}\right)$ and Northeast $\left(\approx 0.018 \mathrm{~s}^{-1}\right)$ areas of the Barents Sea are observed in July - August (Fig. 5). This is due to increased ice melting in summer and, as a consequence, an increase in the density stratification of waters. In the KolguyevoVaigachskiy region, the highest value of the averaged maximum of the buoyancy frequency is observed in May and in August and amounts to $\approx 0.018 \mathrm{~s}^{-1}$. The first peak is associated with the Pechora River runoff effect, the second - with the solar radiation increase and ice melting.

In the Yamalskiy region of the Kara Sea, the maximum values of $\overline{N_{\max }}(z) \approx$ $\approx 0.09 \mathrm{~s}^{-1}$ occur at the beginning of summer (Fig. 6). The Barents Sea water freshened by the waters of Pechora runoffs through the Kara Gate into the Kara Sea, which leads to an increase in the density stratification of waters in the Yamalskiy region ${ }^{2}$. The northern Barents and Kara Seas have similar intraannual variability (Fig. 5, 6), since the West Novaya Zemlya Current supplies the northern regions of the Kara Sea with Atlantic waters, and the Makarov current carries the waters of the Kara Sea to the northern part of the Barents Sea.

${ }^{2}$ Timofeev, V.T., 1946. The Barents Sea Sustainability. Problems of the Artic, (3), pp. 5-7 (in Russian). 
1. Medvezhinskiy.

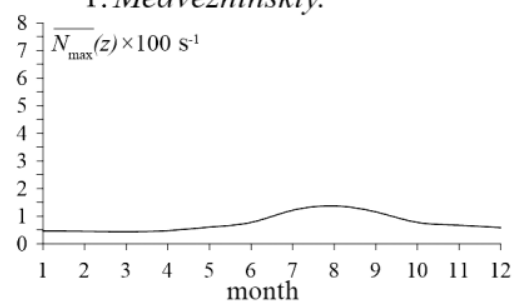

2. Spitsbergenskiy.

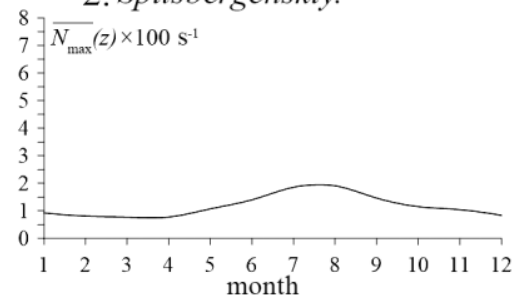

3. North (Barents sea).

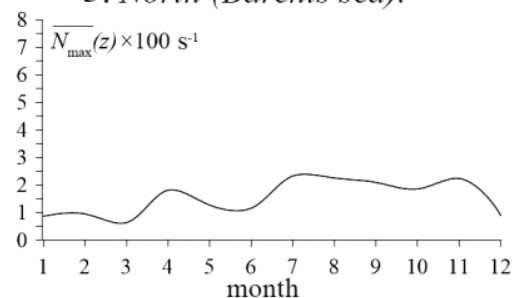

4. Northeast.

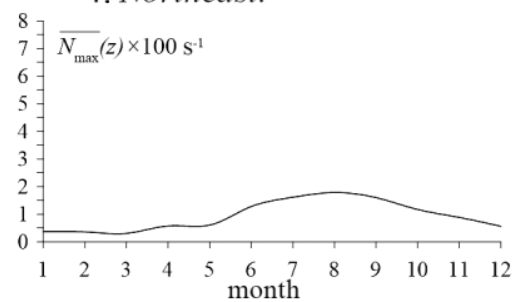

5. Kolguevo-Vaigachskiy.
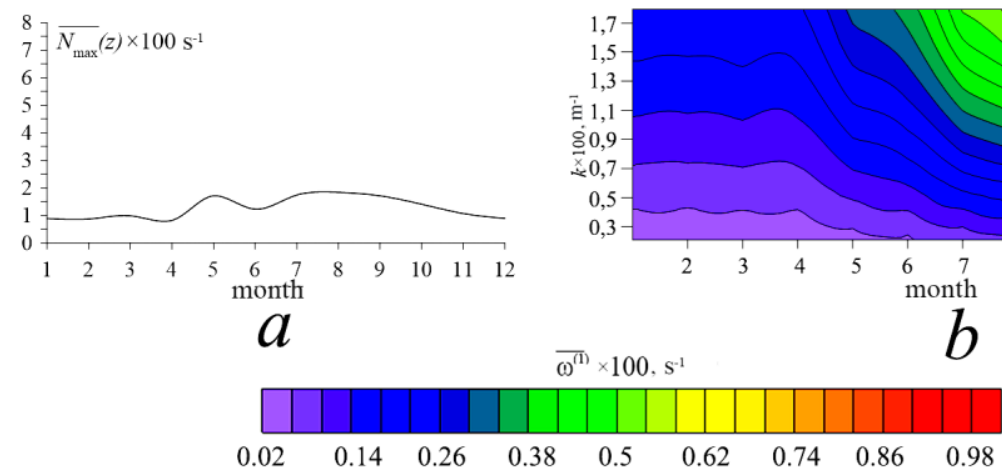
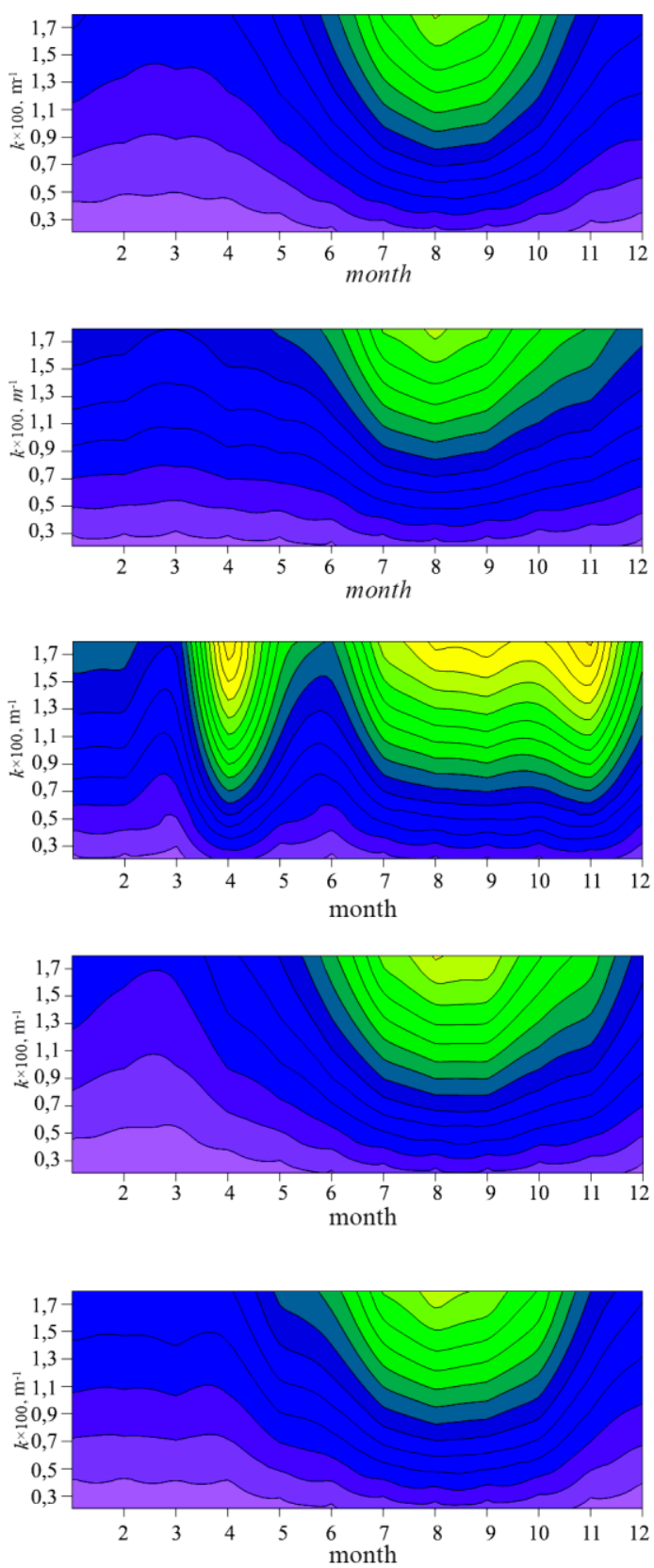

b

F i g. 5. Intra-year variability of the Väisälä-Brunt frequency maximums averaged over the Barents Sea regions $(a)$ and the own frequencies of the internal waves' first mode $(b)$ 
1. Yamalskiy.

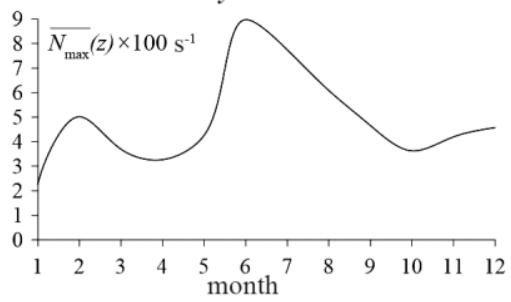

2. Northwest

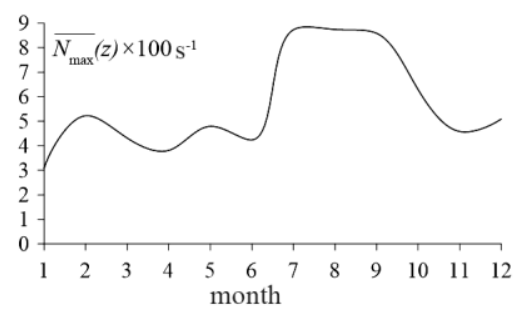

\section{Central.}

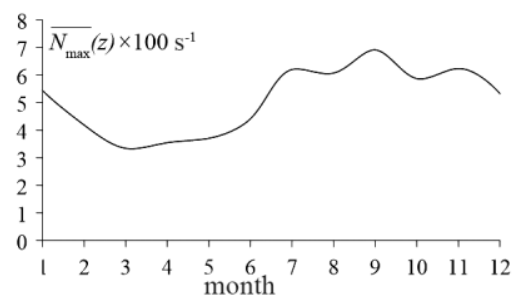

4. North (Kara sea).
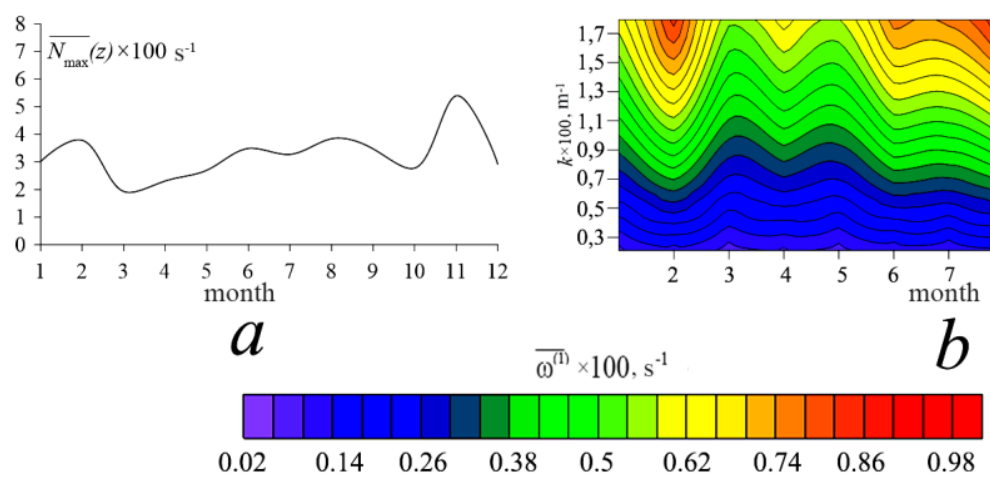
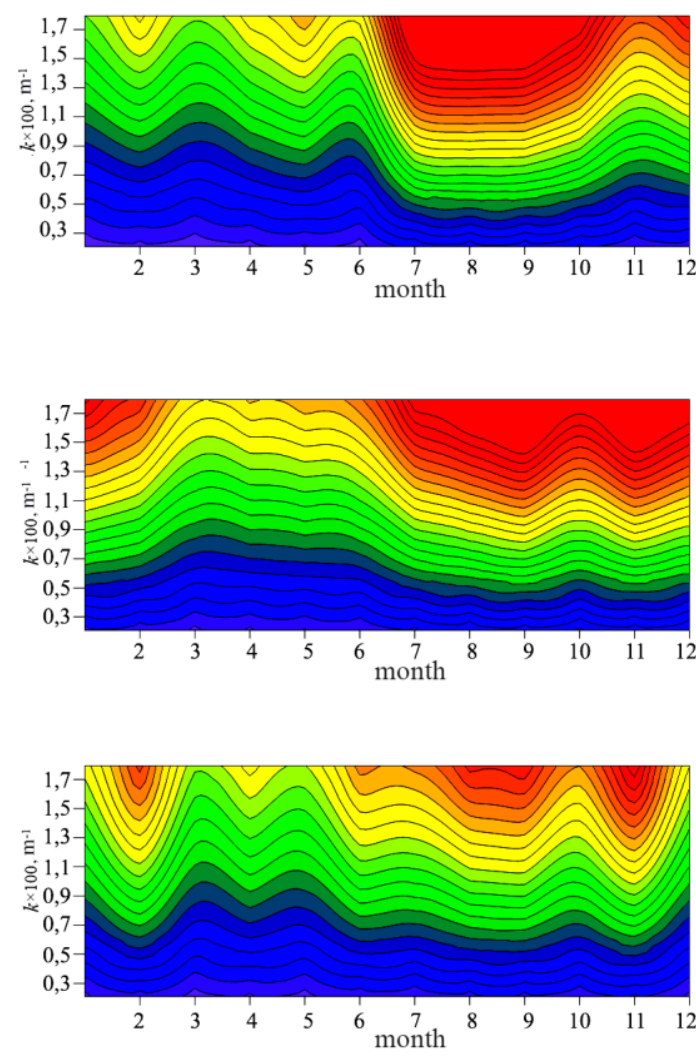

$b$

F i g. 6. Intra-year variability of the Väisälä-Brunt frequency maximums averaged over the Kara Sea regions $(a)$ and the own frequencies of the internal waves' first mode $(b)$

The intra-annual cycle $\overline{\omega^{(n)}}$ is close to the cycle $\overline{N_{\max }}(z)$. The correlation coefficient calculated for intra-annual cycles of the average maximum buoyancy frequency and averaged own frequencies of the first internal wave mode for all regions of the Barents and Kara Seas exceeds 0.9. This is true for other modes of the internal waves. 


\section{Conclusion}

Based on the World Ocean Atlas 2013 data on temperature and salinity, the dispersion properties of free internal waves in the Barents and Kara Seas were studied. As a result of solving of the main boundary value problem of the Sturm Liouville type, the own frequencies of the five lowest modes and the natural frequency of the first mode of internal waves are calculated. The relationship between the vertical structure of the density field and the dispersion properties of free internal waves is analyzed, and the dispersion characteristics of free internal waves are compared based on the analysis of regional hydrological features of the Barents and Kara Seas.

It has been established that in the months of maximum density gradients, the highest-frequency and shortest-period internal waves are observed. In the intraannual cycle, the maximum of the buoyancy depth-averaged over the entire sea area in the Barents Sea reaches its highest values in July and August $\left(\approx 0.02 \mathrm{~s}^{-1}\right)$, in the Kara Sea from July to September $\left(\approx 0.055 \mathrm{~s}^{-1}\right)$ and in November $\left(\approx 0.058 \mathrm{~s}^{-1}\right)$. In the same months, the maximum values of the averaged natural frequencies and the minimum values of the averaged natural period of internal waves are noted.

According to the selected physical and geographical areas, in the Barents Sea the highest values of $\overline{N_{\max }}(z)$ are observed in the North region in July and reach $0.03 \mathrm{~s}^{-1}$. In the Kara Sea, the highest values of $\overline{N_{\max }}(z)$ are observed in June in the Yamalskiy region, in July - September in the Northwest regions and reach $0.09 \mathrm{~s}^{-1}$.

The correlation coefficient between the intra-annual cycle $\overline{N_{\max }}(z)$ and the intraannual cycles $\overline{\omega^{(n)}}$ and $\bar{T}$ internal waves exceeds 0.9 for both the Barents and Kara seas.

\section{REFERENCES}

1. Lavrenov, I.V. and Morozov, E.G., eds., 2002. Surface and Internal Waves in the Arctic Seas. Saint-Petersburg: Gidrometeoizdat, 362 p. (in Russian).

2. Bukatov, A.E., 1974. Internal Waves Generated by Periodic Oscillations of Bottom Region in a Sea with Density Transition Zone. In: MHI, 1974. Marine Hydrophysical Studies. Sevastopol: MHI. Iss. 1, pp. 44-52 (in Russian).

3. Bukatov, A.E., 2017. Waves in the Sea with a Floating Ice Cover. Sevastopol: MHI, 360 p. (in Russian).

4. Bukatov, A.E., Paramonov, A.N., Smirnov, G.V. and Cherkesov, L.V., 1977. Some Resuts of Analysis of Short-Period Internal. In: MHI, 1977. Marine Hydrophysical Studies. Sevastopol: MHI. Vol. 79(4), pp. 250-261 (in Russian).

5. Tomczak, J.M., 1968. Über Interne Wellen in der Nähe der Trägheitsperiode. Deutsche Hydrographische Zeitschrift, 21(4), pp. 145-151. https://doi.org/10.1007/BF02307727

6. Morozov, E.G., 2018. Oceanic Internal Tides: Observations, Analysis and Modeling. Springer, 304 p. doi:10.1007/978-3-319-73159-9

7. Morozov, E.G. and Paka, V.T., 2010. Internal Waves in a High-Latitude Region. Oceanology, 50(5), pp. 668-674. https://doi.org/10.1134/S0001437010050048

8. Locarnini, R.A., Mishonov, A.V., Antonov, J.I., Boyer, T.P., Garcia, H.E., Baranova, O.K., Zweng, M.M., Paver, C.R., Reagan, J.R., Johnson, D.R., Hamilton, M. and Seidov, D., 2013. World Ocean Atlas 2013, Volume 1: Temperature. NOAA Atlas NESDIS 73. Silver Spring, MD: U.S. Department of Commerce, 40 p. 
9. Zweng, M.M., Reagan, J.R., Antonov, J.I., Locarnini, R.A., Mishonov, A.V., Boyer, T.P.,Garcia, H.E., Baranova, O.K., Johnson, D.R., Seidov, D. and Biddle, M.M., 2013. World Ocean Atlas 2013, Volume 2: Salinity. NOAA Atlas NESDIS 74. Silver Spring, MD: U.S. Department of Commerce, 39 p.

10. Bukatov, A.E. and Solovei, N.M., 2017. Evaluation of the Density Field Vertical Structure and the Characteristics of Internal Waves Relation with Large-Scale Atmospheric Circulation in the Peruvian and Benguela Upwelling Areas. Processes in GeoMedia, (2), pp. 485-490 (in Russian).

11. Miropol'skii, Iu.Z., 1981. [Dynamics of Internal Gravitational Waves at the Ocean]. Leningrad, Gidrometeoizdat, 302 p. (in Russian).

12. Gritsenko, V.A. and Krasitsky, V.P., 1982. On a Method for the Computation of Dispersion Relations and Eigenfunctions for Internal Waves in the Ocean from the Field Measurement Data. Oceanology, (4), pp. 545-549 (in Russian).

13. Kozlov, I.E., Kudryavtsev, V.N. and Sandven, S., 2010. Some Results of Internal Waves Study in the Barents Sea Using Satellite Radar Data. Arctic and Antarctic Research, 3(86), pp. 60-69 (in Russian).

14. Gorbatsky, G.V., 1970. Physical-Geographical Zoning Arctic. Part 2: A Strip of Marginal Seas with Islands. Leningrad: LGU, 120 p. (in Russian).

15. Petrov, K.M., 2008. Principles of Physical-Geographical Differentiation of the Arctic Seas: Kara Sea. Izvestiya Akademii Nauk, Seriya Geograficheskaya, (6), pp. 19-30.

16. Bukatov, A.A., Pavlenko, E.A. and Solovei, N.M., 2018. Features of Spatial-Time Variability of Väisälä-Brunt Frequency in Barents and Kara Seas. Processes in GeoMedia, (3), pp. 1004-1013 (in Russian).

About the authors:

Anton A. Bukatov, Senior Research Associate, Marine Hydrophysical Institute of RAS (2 Kapitanskaya Str., Sevastopol, 299011, Russian Federation), Ph. D. (Phys.-Math.), ORCID ID: 0000-0002-1165-8428, ResearcherID: P-6733-2017, newisland@list.ru

Nelya M. Solovei, Junior Research Associate, Marine Hydrophysical Institute of RAS (2 Kapitanskaya Str., Sevastopol, 299011, Russian Federation), ORCID ID: 0000-0003-3359-0345, ne.1e.7@ hotmail.com

Ekaterina A. Pavlenko, Junior Research Associate, Marine Hydrophysical Institute of RAS (2 Kapitanskaya Str., Sevastopol, 299011, Russian Federation), ORCID ID: 0000-0001-9146-5708, mhi.pavlenko@gmail.com

Contribution of the co-authors:

Anton A. Bukatov - statement of the problem, analysis of the research data, analysis and revision of the text

Nelya M. Solovei - development of the program algorithms, analysis of the results of numerical experiments, correction of the paper, reviewing the literature

Ekaterina A. Pavlenko - analysis and validation of results, preparation of graphic materials, preparation of the paper text

All the authors have read and approved the final manuscript.

The authors declare that they have no conflict of interest. 